\title{
The Emperor with No Clothes - Inter-Organizational ICT Cooperation within Municipal Regions
}

\author{
Tomi Dahlberg and Ari Helin \\ University of Turku, Turku School of Economics, Information Systems Science \\ FI-20014 TURUN YLIOPISTO, Finland \\ (tomi.dahlberg, ari.helin) @utu.fi
}

\begin{abstract}
ICT has a significant role in the development and production of municipal services, and in the daily work of municipal civil servants. Yet, municipalities typically develop and operate their ICT activities independently with limited ICT resources, both money and people. Limited resources are the key incentive for inter-municipal ICT cooperation. This article investigates how ICT cooperation is carried out within 20 municipal regions. As the theoretical basis we review transaction cost economics (TCE), resource based view (RBV) and the constructs of Granovetter's social network theory. They are used to outline potential economic and social benefits emerging from ICT cooperation and to describe social mechanisms that influence the realization of such benefits. Our empirical data reveals that there are distinct differences in the effectiveness of ICT activities, in the amount of ICT cooperation and in the governance of ICT cooperation. Our analysis reveals that the emperor will not have clothes ICT cooperation benefits - unless the cooperation is properly organized and governed.
\end{abstract}

Keywords: ICT governance; ICT cooperation; municipalities;

\section{Introduction}

ICT is deployed extensively in the daily municipal activities. It has become an integral part of more or less all municipal activities and services. Municipal civil servants rely on ICT in their work. ICT is deployed to develop and produce social welfare, healthcare, educational, technical and all other services that a municipality provides to its citizens, companies and organizations. It is also widely acknowledged that without ICT municipalities cannot be managed since data about the various activities of municipalities are created, processed, stored and reported with ICT. Moreover, the role of ICT in the activities and services of municipalities appears to be ever increasing. Digitalization of services, digitization of printed and analog legacy materials and Internet of things, for example in infrastructure surveillance, to name just a few emerging ICT deployment areas, are examples of the ever-increasing role of ICT.

adfa, p. 1, 2011 .

(C) Springer-Verlag Berlin Heidelberg 2011 
Yet, municipalities develop and operate ICT activities with limited ICT resources, both money and people. A medium-size municipality in the country of the present study (Finland) with 20000 inhabitants, may have thousands of network-connected devices in offices, schools and other premises of the municipality. In addition to local device specific applications, data and networks, these devices are used to access the dozens/hundreds of information systems (IS) and applications that are used to produce various municipal services. Devices are also provide access to databases, server computers and telecommunication networks that constitute the ICT infrastructure of these IS and applications. Physically ICT infrastructure is usually placed into one or a few data centers. In a medium-size municipality the one data center could be a locked storage room. A medium-sized municipality often has two to five full-time IT specialists to take care and manage all of the above-described ICT. A smaller community with a few thousand inhabitants may have none. It appears as if municipalities had not recognized that their activities and services have become entirely IT-dependent.

The social welfare and healthcare reform in Finland constitutes the background of our research. The National Government decided in late 2015 that 18 municipal regions should have the responsibility for arranging these services from the beginning of 2019. The purpose is that the municipal regions would cooperate also in the arrangement of other municipal services, their ICT included. The data of a countrywide research [1] funded by the Ministry of Finance was made available to our research. The data includes information about Finnish municipalities, such as their size, the number of civil servants, the number of ICT personnel, and the amount of ICT spending. The data also covers the ICT cooperation within 20 municipal regions. We also use data from two other studies [2, 3]. In summary, the purpose of the present study is to investigate how Finnish municipalities cooperate or do not cooperate in ICT by analyzing data made available to us, to outline potential cooperation benefits and to depict social mechanisms that may realize or prevent cooperation and benefit achievement.

In talks, scarcity of ICT resources is regarded as an incentive for ICT cooperation between nearby municipalities. Often heard claims are that with ICT cooperation (nearby) municipalities can pool and share ICT resources, develop and produce similar ICT services together at lower costs per municipality and achieve cost savings by conducting pooled joint hardware and software purchases, which lead to lower unit prices. The transaction cost economics (TCE) theory [4] and the resource based view (RBV) [5] offer theory-based support for the benefits of ICT cooperation. The potential to achieve benefits is what we mean with the emperor having new clothes. On the other hand, municipalities differ in size as well as in economic and industrial structures. These differences and municipalities' constitution-based legal independence have to be taken into account should one wish to engage municipalities into ICT cooperation. The constructs of Granovetter's social network theory $[6,7,8,9]$ offer theoretical explanations, why efforts to establish ICT cooperation may not lead to the emperor actually getting new clothes. 
The objective of our research is demonstrate that the TCE theory and the RBV theory together with the constructs of Granovetter's social network theory provide solid theoretical basis for understanding the potential benefits of ICT cooperation and social mechanisms that influence the ability to achieve such cooperation within the investigated municipal regions. Our second objective is to understand what are the current status in the effectiveness of ICT activities within the investigated municipalities as well as the status of the inter-organizational ICT cooperation in terms of the volume and depth of ICT governance. To achieve these objectives we raise the following research questions:

1. How do Finnish municipalities cooperate currently in ICT and how is ICT cooperation organized?

2. What ICT cooperation benefits and possibilities have Finnish municipalities identified and do the identified benefits and opportunities act as antecedents for willingness to engage into (formal) inter-organizational IT governance arrangements?

3. If ICT cooperation between Finnish municipalities is organized on the basis of an (formal) inter-organizational IT governance arrangement or alternatively on the basis of an ad-hoc arrangements, do those alternatives impact the achievement of ICT cooperation and cooperation benefits?

The rest of the paper is organized as follows. As the theoretical background of our study we depict what potential benefits the TCE theory and the RBV approach propose for inter-organizational ICT cooperation. In the theoretical background section we also describe how social network theory constructs impact the achievement of ICT cooperation benefits. We then explicate our research methods and the characteristics of the empirical data sets used in the data analysis. After the results of the study are disclosed we end the article with a discussion of its scientific and practical contributions and conclusions for researchers and practitioners.

\section{Theoretical Background}

\subsection{TCE and RBV and the Economic Benefits of ICT Cooperation}

The transaction cost economics theory calls economic transactions inside a single organisation (make) as vertical governance, and transactions between a buyer and a seller as market governance (buy). Market governance transactions with one principal and several subcontractors establish a hierarchical network and transaction in alliances and networks constitute relational, also known as networked, governance [4], [10]. Inter-organizational cooperation between municipalities falls into the category of relational governance. The rationale of the TCE theory is that an organization (municipality) should rely on that form of governance that provides lowest transaction costs [11]. TCE proposes that market governance, such as reliance on municipal ICT coop- 
eration, is most viable when assets are non-idiosyncratic, the use of assets is voluminous or very small and the uncertainty related to asset usage outcomes can be lowered [4], [10], [11]. The simplistic interpretation is that municipalities should conduct ICT cooperation in issues that are similar to all of them and where they are able to reduce risks (uncertainty) by cooperation. Cumulatively, TCE research has identified dozens of cost-inclusive and cost-exclusive metrics [11] to measure the cost savings of asset specificity, uncertainty and frequency.

The resource based view approach considers each organisation as unique [5], [12]. An organisation (municipality) is equivalent to the broad set of resources that the organization owns at least (semi-) permanently [13]. These resources as a whole - especially those resources that are imperfectly mobile, imitable, and substitutable - define the value creation potential of the organisation. Thus the RBV approach focuses on how to add value when TCE focuses on how to save costs. The idea of RBV is that and organization (municipality) should rely inter-organisational (municipal ICT) cooperation if that provides more value to cooperation participants through pooling, aggregating, sharing, and exchanging their unique resources. For cooperation to happen it is also necessary that added win-win value couldn't be achieved easily in other ways. The conclusion is similar to the TCE theory. Municipalities should cooperate in ICT, when they face similar issues and when cooperation provides measurable value to all of them. Value increases detected in RBV research are classified into the following categories: conserve resources, share risks, obtain information, access complementary resources, reduce product development costs, improve technological capabilities, and enhance reliability [14].

\subsection{Constructs of Granovetter's Social Network Theory}

We use the constructs of Granovetter's social network theory to understand why the ICT cooperation potential between municipalities happens or is prevented. Other theories about social structures and mechanisms fall outside the scope of our study. For example, we do not use the social network analysis approach [15], in which connections between the individuals of a network are crafted into a matrix and analyzed to detect such properties of the network as cohesion, centralicity and power.

Social networks affect the flow and the quality of information between individuals as well as the trust that other individuals do the right things in a social network [9]. Also the TCE theory emphasizes the importance of trust as a property of relational governance. Existence of trust is seen to impact positively both the creation and the performance (of municipal ICT) cooperation [11]. The same view is present also in RBV. Prior studies have reported that the lack of trust reduces willingness to cooperate. These findings justify the inclusion of social network theory constructs into the theoretical background of our research, since social network theory constructs explain the existence or lack of trust [13]. 
The density of a network is the first relevant construct [9]. The denser a network the easier it is to enforce norms to the network, i.e. agree the objectives of municipal ICT cooperation. The practical interpretation is that should there be close long-term and focused cooperation between municipalities in ICT, then more results could be expected. The research [2] to be reviewed in Section 2.3 discovered that the past history of municipal ICT cooperation in Finland could best be described with words ad-hoc cooperation and non-existence of organized ICT governance. The larger a network the lower the network density, because people have cognitive, emotional, spatial and temporal limits on how many social ties they are able sustain [7], [9]. Sparse networks (low density) may explain why municipal ICT professionals have not cooperated even if that would help them professionally.

Any organization consists of several different social groups, to which individuals are connected with strong ties. Through weak ties, the second relevant concept, individuals are connected to groups outside their own social circle. Weak ties between organizational groups provide access to information and resources beyond those available in one's own social circle [6,7]. The practical meaning is that should there be long-term and frequent communicative connections between the ICT experts of municipalities, then that would have positive impacts on ICT cooperation and benefits achievement.

The structural hole construct [9] extends the weak ties construct. The structural hole construct proposes that is even more important that different parts of a network are connected than what is the nature of ties. The practical implication is that the lack of long-term and frequent connections between municipal ICT experts will influence ICT cooperation negatively. Social embeddedness, also called the interpenetration of economic and non-economic action [8], is the final relevant construct discussed. The performance objectives of ICT cooperation typically have strong economic incentives. Ability to save IT cost or to develop ICT services efficiently are examples of such incentives. On the other hand, social connections are largely non-economic [9]. The practical implication is that the outcomes of ICT cooperation between municipalities should not based only on economic objectives and metrics but also on social metrics, for example on the development of professional competencies through knowledge and best practices sharing.

\subsection{Previous Research on the ICT Cooperation between Finnish Municipalities}

Our previous study [2] described, how inter-organizational IT governance was established between five hospital districts, 68 municipalities and 33 healthcare centers in Finland during the years 2013-2014. In the present study we depict only that part of article, which addresses the expected benefits of systematic inter-organizational IT governance. The establishment of the inter-organizational ICT governance arrangement [2] resulted in the discovery of 13 perceived ICT cooperation benefits shown in 
Table 1. Fifteen individuals representing the mentioned hospital districts, municipalities and healthcare centers defined the benefit statements of Table 1 in cooperation. They also crafted and implemented the inter-organizational ICT cooperation governance arrangement to realize the identified cooperation benefits [2]. To validate the identified cooperation benefits a national survey was arranged to do that. An invitation to participate to the survey was sent to 240 social welfare and healthcare specialists and 68 valid responses were received. A respondent was requested to evaluate each of the 13 benefit statements. A 7-step Likert scale from fully agree with the benefit statement (response value $=7$ ) to fully disagree with the benefit statement (response value $=1$ ) was used in the survey. Table 1 shows the proportion of responses that either fully (response value $=7$ ) or strongly agreed (response value $=6$ ) with a benefit statement. Table 1 also shows the connection of the benefit statements to TCE and RBV, which were used to craft the benefit statements [see 2].

Table 1. Perceived benefits of ICT cooperation between municipalities

\begin{tabular}{||l|c||}
\hline $\begin{array}{l}\text { Perceived benefit of inter-organizational ICT cooperation in } \\
\text { municipal healthcare and social welfare ICT with links to } \\
\text { theoretical TCE and RBV constructs [2] }\end{array}$ & $\begin{array}{c}\text { Proportion } \\
\text { of strongly } \\
\text { agree (n=68) }\end{array}$ \\
\hline \hline $\begin{array}{l}\text { Avoid the development of overlapping and difficult to integrate IT } \\
\text { services (RBV- conserve resources; TCE - asset specificity) }\end{array}$ & $86.8 \%$ \\
\hline $\begin{array}{l}\text { Increase the interoperability of patient/customer information sys- } \\
\text { tems and data storages (RBV - obtain resources; TCE - asset specificity }\end{array}$ & $86.8 \%$ \\
\hline Create enterprise architectures (RBV - substitute; TCE reduce uncertainty) & $79.4 \%$ \\
\hline $\begin{array}{l}\text { (Co-)source IT-services cost-efficiently and effectively (RBV - } \\
\text { create difficult to imitable resources; TCE - reduce cost of non-specific assets) }\end{array}$ & $75.0 \%$ \\
\hline $\begin{array}{l}\text { Implement national level healthcare and social welfare IT services } \\
\text { efficiently and effectively (RBV - access to resources that are difficult to } \\
\text { imitate; TCE - acquire assets that are specific at low costs) }\end{array}$ & $75.0 \%$ \\
\hline $\begin{array}{l}\text { Ensure ability to participate to the national level development of } \\
\text { healthcare and social welfare services (RBV and TCE as above) }\end{array}$ & $72.1 \%$ \\
\hline $\begin{array}{l}\text { Use IT resources and assets efficiently and effectively (RBV and } \\
\text { TCE - all key constructs of both theories) }\end{array}$ & $70.6 \%$ \\
\hline $\begin{array}{l}\text { Ensure access to specialized capabilities and competencies every- } \\
\text { where in the area (RBV - ensure access to rare resources; TCE - ensure avail- } \\
\text { ability of idiosyncratic assets) }\end{array}$ & $69.1 \%$ \\
\hline $\begin{array}{l}\text { Ensure availability of equal healthcare and social welfare services } \\
\text { everywhere in the area (RBV and TCE as above) }\end{array}$ & $67.6 \%$ \\
\hline $\begin{array}{l}\text { Tighter cooperation on national level (RBV - substitute resources; TCE } \\
\text { reduce uncertainty) }\end{array}$ & $89.7 \%$ \\
\hline $\begin{array}{l}\text { Tighter cooperation on regional level (this area) (RBV - share unique } \\
\text { resources; TCE - reduce the impact of idiosyncratic assets) }\end{array}$ & $85.3 \%$ \\
\hline $\begin{array}{l}\text { The creation of jointly agreed data models and sticking to them } \\
\text { (RBV - value through pooling; TCE reduce uncertainty) }\end{array}$ & $85.3 \%$ \\
\hline $\begin{array}{l}\text { Tighter cooperation between healthcare and social welfare (RBV - } \\
\text { create substitute value; TCE - reduce behavioral uncertainty) }\end{array}$ & $79.4 \%$ \\
\hline
\end{tabular}


On the basis of the survey it is evident that the similar ICT cooperation benefits are available to other municipalities.

\section{Methodology}

Our empirical research material consists of information from three case studies. One of them was a large research that covered most Finnish municipalities and the two other researches were regional case studies in Northern Finland and Northern Ostrobothnia. The empirical research material of [1] was collected in a research conducted by the Ministry of Finance. The purpose of their research was to support municipalities in their efforts to restructure municipal services. The name of the research was "ICT change support program" (ICT-muutostukiohjelma). Cumulatively 144 out of the country's 317 municipalities participated into this research during 20.2.2014 31.12.2015. Municipalities were grouped into 20 regional areas. Each group produced a report on ICT within its regional area. We analyze the data as secondary data.

The empirical research material includes information about participating municipalities. The following background information was collected: name of the municipality, number of ICT personnel, the proportion of ICT personnel from the total number of municipal civil servants, the format of municipal cooperation and the names of participating municipalities in the regional cooperation. From data we collected comments and observations on the following topics: the format of municipal cooperation, the core of ICT cooperation, other cooperation entities, and ownership in Kuntien Tiera Oy. Kuntien Tiera is a nationwide ICT service company owned by municipalities. To verify the size of population in each municipality, we used data provided by the Finnish Population Register Center (Väestörekisterikeskus) [16].

Research material contained 20 reports on regional municipal areas as participating municipalities were divided into 20 regional areas. Each regional area was considered as the candidate of municipal mergers between the municipalities of the area. The eleven largest urban areas of the country were included. The number of municipalities varied between 3 and 17. Three regional reports followed a different approach to the other 17 regional reports. These three reports focused only to specific details or future scenarios. Due to the inconsistencies between these three and the other 17 reports we excluded them from data analysis.

We read all remaining 17 reports and classified information in them as explained earlier. Still, it is necessary to note that the approaches and the content of the 17 reports are not fully compatible and comparable. The reason is that consultants wrote the regional reports. This resulted in report inconsistencies. Information collected and analyzed in the present study was, however, mostly available. 
As mentioned, in addition to the research material made available to us by the Ministry of Finance, we used data from two other case studies. Mentioned studies reported well-organized ICT cooperation and/ or governance arrangements between municipalities.

\section{$4 \quad$ Results}

\subsection{ICT Cooperation between Municipalities (Research Question 1)}

The size of the population in municipalities ranged from 755 inhabitants to 623732 inhabitants [16]. Due to the large variability in the population size of municipalities, also the number of civil servants and the number of ICT personnel employed by municipalities varied a lot. The number of ICT personnel varied from zero to $483 \mathrm{em}$ ployees. Statistics on the number of ICT personnel was compiled into table 2.

Table 2. The number of ICT personnel

\begin{tabular}{|c|c|}
\hline Number of ICT personnel & Number of municipalities \\
\hline 0 & 27 \\
\hline$<=1$ & 26 \\
\hline $1<2$ & 8 \\
\hline $2-9$ & 35 \\
\hline $10-49$ & 7 \\
\hline $50-99$ & 4 \\
\hline $100+$ & 3 \\
\hline No information/unknown & $29 / 5$ \\
\hline
\end{tabular}

Most small municipalities had no or very few ICT experts. Table 2 indicates that 27 municipalities, almost $20 \%$ of the 139 municipalities, did not have any ICT expert. In addition to that, 26 municipalities reported that the number of ICT personnel is less than one. In these 26 municipalities, other municipal civil servants carried out ICT tasks in addition to their other duties or a part-time person had been recruited. Twenty-nine plus five municipalities did not report the number of ICT personnel or the numbers of ICT personnel were summed up to the total number of ICT personnel in a regional report. The comparison between the number of ICT personnel and the number of municipal civil servants revealed that the ratio varied from 0 and 2.4 percent. Two point four percent was detected in a very small municipality, where one ICT professional was sufficient to produce this ratio. The ratio of ICT personnel to total number of municipal civil servants was above one percent in only 9 municipalities. Seven of them had less than 3300 inhabitants. The other two municipalities are among the five largest municipalities in Finland. There appears to be no correlations between 
the size of the population in a municipality, the number of municipal civil servants and the number of ICT personnel. We did, however, not perform any statistical tests.

Data on the depth of ICT cooperation was also compiled from the regional reports. Table 3 was created by classifying the comments and feelings of persons that participated into the research conducted by the ministry. Deep or fairly deep cooperation can be interpreted as regular, (semi-)official cooperation. Limited and very limited cooperation means ad-hoc cooperation with information sharing from time to time. As table 3 illustrates limited ICT cooperation between nearby municipalities was more common than deep cooperation.

Table 3. Municipal ICT cooperation

\begin{tabular}{|c|c|}
\hline Depth of ICT cooperation & Number of regions $(\mathrm{n}=20)$ \\
\hline Deep & 3 \\
\hline Fairly deep & 3 \\
\hline Some & 4 \\
\hline Limited & 9 \\
\hline Very limited & 1 \\
\hline
\end{tabular}

ICT cooperation between municipalities is most often conducted in healthcare and social welfare ICT. The insufficiency of ICT resources, both financial and human, was the most often mentioned reason for the lack of ICT cooperation. The number of ICT personnel is so small that it has been necessary to allocate all resources to keep the operational ICT systems running. That left no ICT experts to municipal ICT cooperation or to joint development of ICT services. The infamous double bind (catch-22) concept could be used to describe this finding.

Even though ICT cooperation between municipalities appears to be limited in Finland, largely due to lack of time available, municipalities have cooperated since times immemorial. The Constitution and other laws allow Finnish municipalities to organize their service production in multiple ways. It often makes sense to join forces and organize the production of services together. The history of municipalities has witnessed several forms of cooperation. One common practice is to create a joint authority to take care of a specific service area. There were 136 such joint authorities in 2012 in Finland. A joint authority is an independent public entity, which operates under the legislation governing the activities of municipalities and is "owned" by the cooperating municipalities. Healthcare districts are the largest joint authorities. Municipalities may also jointly hire civil servants to produce selected services. Especially smaller municipalities use this option. Municipalities have established jointly owned enterprises to take care of waste management, business services and tourism. They have also signed cooperation agreements to execute such services as water management, rescue services, educational activities and the inspection of buildings. Municipalities may even buy services from other municipalities, should that make economic sense. 
Regional cooperation between municipalities within a specific service area has traditionally been associated with industrial policy and lobbying [17]. We find it surprising that municipalities have established only a few joint ICT authorities, such as Kuntien Tiera, to ensure that benefits described in section 2.3 could be obtained. We feel that sparse networks with structural holes and lack of weak tie, which make true cooperation possible, are important determinants for this phenomenon.

\subsection{Perceived Benefits and Potential of Municipal ICT Cooperation (Research Question 2)}

Our data analysis showed that ICT cooperation between municipalities is most often loose and based on ad-hoc arrangements. Sixteen out of the 17 regional areas were willing to consider ideas on how to organize municipal ICT cooperation better, as Table 4 indicates.

Table 4. Development ideas to improve municipal ICT cooperation

\begin{tabular}{|l|c|}
\hline Development idea to improve ICT cooperation & $\begin{array}{c}\text { Number of areas willing to } \\
\text { consider the idea }(\mathrm{n}=16)\end{array}$ \\
\hline Data center cooperation or server cooperation & 9 \\
\hline Joint procurement & 7 \\
\hline Shared development, national cooperation & 6 \\
\hline Development cooperation with a municipal group & 3 \\
\hline Buying shares in an existing company or organization & 2 \\
\hline Establishment of a new, shared service ICT company & 2 \\
\hline Discussion forums & 1 \\
\hline Mergers between municipalities & 3 \\
\hline
\end{tabular}

Fourteen of the regional reports included data on more detailed development ideas for municipal ICT cooperation. We have compiled these results into Table 5. The titles of the development ideas are shown as expressed by the participants.

Table 5. Detailed development ideas for municipal ICT cooperation

\begin{tabular}{|l|c|}
\hline Detailed development idea & $\begin{array}{c}\text { Number of re- } \\
\text { sponses ( } \mathrm{n}=14)\end{array}$ \\
\hline Integration of IS & 11 \\
\hline Centralization of ICT infrastructure & 8 \\
\hline Development of (regional) digital services & 7 \\
\hline Renewal of ICT model & 6 \\
\hline Process harmonization & 5 \\
\hline Organization and development of ICT expert resources & 4 \\
\hline Development of operating models & 4 \\
\hline
\end{tabular}




\begin{tabular}{|l|l|}
\hline Closer cooperation between business and ICT management & 3 \\
\hline Harmonization of contracts & 3 \\
\hline Joint development of ICT governance models & 3 \\
\hline Joint Strategic Management of ICT & 3 \\
\hline Shared ICT service operations, ICT service strategy & 3 \\
\hline Development of a common guidance & 2 \\
\hline Development of ICT awareness among municipal managers & 2 \\
\hline Development of special knowledge & 1 \\
\hline Development of ICT design activities & 1 \\
\hline Development of ICT design methods & 1 \\
\hline Shared management of ICT governance models & 1 \\
\hline Identification of ICT services for core business & 1 \\
\hline
\end{tabular}

Seven regional reports contained data on regional development projects. We compiled that data into Table 6 . Project names are labeled as expressed by the participants.

Table 6. Local development projects

\begin{tabular}{|l|c|}
\hline Local development project & $\begin{array}{c}\text { Number of times men- } \\
\text { tioned }(\mathrm{n}=7)\end{array}$ \\
\hline Electronic transactions and archiving & 7 \\
\hline Electronic meeting practices & 4 \\
\hline Master data management & 4 \\
\hline Learning solutions & 4 \\
\hline Document management, records management and archiving & 4 \\
\hline Data management, knowledge management & 3 \\
\hline Definition of processes & 3 \\
\hline Organization and user rights management & 3 \\
\hline Integration principles of systems, data and the solutions & 3 \\
\hline Project Portfolio and Project Management & 3 \\
\hline ICT model & 2 \\
\hline Service portfolio definition & 2 \\
\hline Intranet systems development and integration & 2 \\
\hline User support, desktop support & 2 \\
\hline Knowledge management & 1 \\
\hline Reporting principles & 1 \\
\hline Project work method & 2 \\
\hline
\end{tabular}

In the regional reports, several municipalities described their ICT cooperation with other municipalities as loose and based on ad-hoc arrangements. Civil servants and ICT professionals meet and diverse topics are discussed. Yet, since no formal ICT governance arrangement has been established topics remain open. ICT cooperation 
regarding more detailed development ideas is also described as loose and ad-hoc. Our previous study [2] described a similar situation prior the establishment of a formal ICT governance arrangement. Our conclusion is that the establishment of interorganizational ICT governance receives little support among the ICT professionals working in municipalities, as the necessary social network structures do not exist. ICT professionals have proposed many ideas on how to improve current ICT cooperation between municipalities but are reluctant to improve ICT governance as a primary short-term activity since there is no trust. On the other hand, several cooperation benefits were mentioned as tables 4, 5 and 6 showed. Also several detailed ICT cooperation development ideas, such as the renewal of ICT model, development of operational models, joint development of ICT governance models, and joint strategic management of ICT. At least some municipal ICT experts recognize the need to establish better-organized ICT cooperation and governance arrangements. We conclude that the necessary activities is to build necessary social ties to facilitate trust building prior to or in the connection of more formal ICT cooperation arrangements.

The regional reports reveal that among the 20 regions ICT governance is advanced in one particular region. That region consists of one major city and 8 smaller municipalities surrounding the city. These 8 municipalities have established an alliance, which manages and develops ICT for all municipalities and manages the relationship to the major city. Municipalities have recruited a shared ICT Director. The ICT director represents participating municipalities in relevant forums and the salary is divided between the municipalities. The ICT governance arrangement aligns ICT management activities with the major city and the municipalities. Two ICT executive committees have been organized, one with the major city and another with the surrounding municipalities. The major city and the municipalities still have their own projects, working groups and meetings to make their own decisions. Ability to provide alternatives and mobility to customers with shared regional learning environments, regional public transportation and well-functioning administration are some of main objectives in the regional inter-organizational ICT cooperation Both the major city and the surrounding municipalities have been pleased with the ICT governance arrangements and the progress of municipal ICT cooperation.

In two other cases, ICT governance was an explicitly stated objective. The project conduced in northern Finland expressed: "the purpose of the agreement and the specified ICT cooperation is to sharpen and clarify ICT steering, and to thus enhance the service capability and productivity of ICT" [3]. Participating municipalities have agreed shared objectives and development areas for municipal inter-organizational ICT cooperation. Municipalities have also signed cooperation and project agreements, and have started the implementation of shared projects. According to data available ICT cooperation has progressed well based on the inter-organizational ICT governance. The data of the other case study [2] provides similar results. 


\subsection{The Impacts of Inter-Organizational IT Governance (Research Question 3)}

On the basis of the research funded by the Ministry of Finance and two separate case studies, well organized ICT cooperation and governance has indisputable positive impacts on ICT activities and services. Business and ICT professional are more satisfied. ICT activities and services have clearer objectives. The establishment of wellorganized ICT cooperation and governance arrangement also helps to solve challenges that limited ICT resources create in municipalities. Why have ICT professionals in municipalities not used these opportunities? ICT professionals appear not have the time. Yet, we propose that the real reason is also related to the deficiencies in intermunicipal social networks. Social networks are needed to build trust and to share information between municipalities with different sizes and priorities.

We summarize our results to the three research questions with the metaphor we used in the title of this article. The emperor (municipalities) would like to have new clothes (improve ICT cooperation to receive benefits). Only after the establishment of wellorganized ICT cooperation governance, are they able to realistically to get new clothes (benefits from ICT cooperation based on concrete development ideas and objectives).

\section{$5 \quad$ Discussion and Conclusions}

The purpose of the present study was to investigate how Finnish municipalities cooperate in ICT by analyzing secondary data and to explain connections between empirical findings and theoretical constructs. Data analyzed indicated that Finnish municipalities run their ICT largely alone without well-organized ICT cooperation. The Constitution of Finland [19] stipulates that municipalities are independent selfgoverned entities. Thus they have the right to do so. On the other hand, there are several reasons for municipal ICT cooperation between (nearby) municipalities with significant economic and other benefits. The size of a municipality is often small in comparison to ICT investment and development needs, ICT resources and their availability to a municipality is limited, the development of municipal services are increasingly ICT-enabled and various reforms of municipal services require more investments into ICT and digitalization. These are strong drivers for cooperation between municipalities.

We discovered that municipalities consider ICT cooperation between municipalities important. Expectations and perceptions about the potential benefits of ICT cooperation are both economic and non-economic. The transaction cost economics theory and the resource based view approach are able to describe expected economic benefits. Yet, active cooperation among municipalities was detected to be relatively rare as municipalities struggled with their limited ICT resources to keep their operative ICT running. This situation leaves little if any room for ICT development and ICT cooperation with nearby municipalities. We discovered three regions where ICT cooperation 
between municipalities was more advanced. Each of these three regions had a slightly different approach to ICT cooperation. One region had a shared ICT management function, another region a jointly owned ICT service company and the third area inter-organizational ICT governance arrangement. Despite of the differences these three regions perceived that ICT cooperation progressed and delivered benefits due to clearly organized ICT cooperation and accountabilities. The contrast to regions with little ICT cooperation was clear. Municipalities in these regions were dissatisfied with ICT cooperation. Due to the lack of coopeation ideas on how to improve their situation were not implemented. The constructs of the social network theory, especially network density, weak ties and structural holes explain differences between the perceptions of those who cooperate actively and those who do not. These are our responses to the three research questions and the objectives stated in the beginning of our article.

Our study was conducted in one country and caution with the results of our research is necessary. The empirical data contained only few cases with active ICT coopeation between Finnish municipalities, which is another limitation. Evidence to properly analyze well-organized and disorganized ICT cooperation is limited. These limitations can hopefully be removed with future studies by conducting similar studies in other countries and by continuing data collection on ICT cooperation outside of the 20 municipal regions and the two cases. In addition to academic contributions such research could also have practical value. Inter-organizational ICT cooperation between municipalities starts often gradually. ICT professionals want to discuss professional matters with their colleagues and share experiences. That may lead to better-organized cooperation and, as our study shows, to more benefits when ICT cooperation is well organized. We once more underline the role of social ties.

Our advice to researchers is to especially investigate the social mechanism of interorganizational ICT governance. Our advice to practitioners is to take the time and effort to establish a well-organized arrangement for ICT cooperation and governance. In doing so they should consider how to secure strong flow of economic and social information between the cooperating municipalities and persons.

\section{References}

1. Ministry of Finance, https://wiki.julkict.fi/julkict/Kuntauudistus/ictmuutostuki-1. Downloaded 30.11.2015.

2. Dahlberg, T.: The Creation of Inter-organisational IT Governance for Social Welfare and Healthcare IT - Lessons from a Case Study. IJNVO. Vol. 16, No 1, pp. 38-71 (2016)

3. ePS2, Tietohallintoyhteistyö, Kari Hyvönen, presentation material 4.11.2015 
4. Williamson, O.E.: Markets and Hierarchies: Analysis and Antitrust Implications - A Study in the Economics of Internal Organization, The Free Press, New York (1975)

5. Wiengarten, F., Humphreys, P., Cao, G. and McHugh, M.: Exploring the important role of organizational factors in IT business value: Taking a contingency perspective on the resource-based view. Int J Manag Rev. Vol. 15 No. 1, pp. 30-46 (2013)

6. Granovetter, M.S.: The strength of weak ties. Am J Sociol. Vol. 78, No. 6, pp. 1360-1380 (1973)

7. Granovetter, M. S.: The Strength of Weak Ties: A Network Theory Revisited. Sociological Theory. pp. 201-233 (1983)

8. Granovetter, M.S.: Economic action and social structure: The problem of embeddedness. Am J Sociol. Vol. 91, No. 3, pp. 481-510 (1985)

9. Granovetter, M.S.: The Impact of Social Structure on Economic Outcomes. J Econ Perspect. (19:1), pp. 33-50 (2005)

10. Williamson, O.E.: The Economic Institutions of Capitalism, The Free Press, New York (1985)

11. Geyskens, I., Steenkamp, J.-B.E.M. and Kumar, N.: Make, buy, or ally: A transaction cost theory meta-analysis. Acad Manage J. Vol. 49 No. 3, pp. 519-543 (2006)

12. Barney, J.: Firm resources and sustained competitive advantage. J Manage. Vol. 17, No. 1, pp. 99-120 (1991)

13. Das, T.K. and Teng, B.-S.: A resource-based theory of strategic alliances. J Manage. Vol. 26, No. 1, pp. 31-61 (2000)

14. Park, N.K., Mezias, J.M. and Song, J.: A resource-based view of strategic alliances and firm value in the electronic marketplace. J Manage. Vol. 30, No. 1, pp. 7-27 (2004)

15. Scott, J.: Social Network Analysis. Third edition. Sage publications Ltd., London (2013)

16. Väestörekisterikeskus, http://vrk.fi/default.aspx?docid $=8816 \&$ site $=3 \& i d=0$. Downloaded 17.3.2016.

17. Kuntaliitto, http://www.kunnat.net/fi/kunnat/toiminta/yhteistoiminta/Sivut /default.aspx. Downloaded 24.3.2016

18. The Constitution of Finland, Ministry of Justice, Finland, http://www.finlex.fi/en/laki/kaannokset/1999/en19990731.pdf. Downloaded 21.3. 2016. 